\title{
Trends in hepatitis B virus screening at the onset of chemotherapy in a large US cancer center
}

\author{
Jessica P Hwang ${ }^{*}$, Michael J Fisch ${ }^{4}$, Anna S-F Lok ${ }^{2}$, Hong Zhang ${ }^{1}$, John M Vierling ${ }^{3}$ and Maria E Suarez-Almazor ${ }^{1}$
}

\begin{abstract}
Background: National organizations recommend screening for hepatitis B virus (HBV) before chemotherapy but differ regarding which patients should be screened. We aimed to determine contemporary screening rates at a cancer center and the possible influence on these rates of publication of national recommendations.

Methods: We conducted a retrospective cohort study of HBV screening in cancer patients registered during the period from January 2004 through April 2011. Screening was defined as HBsAg and anti-HBc tests ordered around the time of initial chemotherapy. We compared screening rates for 3 periods: January 1, 2004, through December 18, 2008 (Food and Drug Administration and American Association for the Study of Liver Diseases 2007 recommendations); December 19, 2008, through September 30, 2010 (Centers for Disease Control and Prevention, National Comprehensive Cancer Network, American Association for the Study of Liver Diseases 2009, Institute of Medicine, and American Society of Clinical Oncology recommendations); and October 1, 2010, through April 30, 2011. Logistic regression models were used to identify predictors of screening.
\end{abstract}

Results: Of 141,877 new patients, 18,688 received chemotherapy, and 3020 (16.2\%) were screened. HBV screening rates increased over the 3 time periods $(14.8 \%, 18.2 \%, 19.9 \%$; $P<0.0001)$, but $<19 \%$ of patients with HBV risk factors were screened. Among patients with hematologic malignancies, over $66 \%$ were screened, and odds of screening nearly doubled after publication of the recommendations $(P<0.0001)$. Less than $4 \%$ of patients with solid tumors were screened, although odds of screening increased $70 \%$ after publication of the recommendations $(P=0.003)$. Other predictors of screening included younger age, planned rituximab therapy, and known risk factors for HBV infection.

Conclusions: Most patients with solid tumors or HBV risk factors remained unscreened, although screening rates increased after publication of national recommendations. Efforts are needed to increase awareness of the importance of HBV screening before chemotherapy to identify patients who should start antiviral prophylaxis.

Keywords: Hepatitis B virus, Hepatitis B virus screening, Chemotherapy, Reactivation

\section{Background}

National [1-7] and international [8,9] recommendations for hepatitis $\mathrm{B}$ virus (HBV) screening before chemotherapy emphasize the need to identify patients with HBV infection so that antiviral prophylaxis can be initiated to prevent reactivation of $\mathrm{HBV}$ infection. The pooled (range) incidence of HBV reactivation, HBV-related hepatitis, HBV-related liver failure, and HBV-related death among cancer patients receiving chemotherapy, who had not received antiviral

\footnotetext{
* Correspondence: jphwang@mdanderson.org

'Department of General Internal Medicine, The University of Texas MD Anderson Cancer Center, 1515 Holcombe Blvd., Unit 1465, Houston, Texas 77030, USA

Full list of author information is available at the end of the article
}

prophylaxis has been reported to be $37 \%$ (24-88\%), 33\% (24-88\%), 13\% (5-33\%) and 7\% (0-63\%), respectively [10]. The 7 national recommendations, however, differ regarding which patients should be screened [1-7] (Table 1). Unfortunately, no population-based studies have been conducted in the US to inform an evidence-based HBV screening policy.

Although the rates of HBV screening before immunosuppressive therapy in the US are unknown because of the lack of large-scale studies, rates have been estimated through physician surveys, which have shown rates ranging from $38-80 \%$ [11-13]. However, these studies were limited by the potential for recall bias and low survey

\section{Biomed Central}

(c) 2013 Hwang et al.; licensee BioMed Central Ltd. This is an open access article distributed under the terms of the Creative Commons Attribution License (http://creativecommons.org/licenses/by/2.0), which permits unrestricted use, distribution, and reproduction in any medium, provided the original work is properly cited. 
Table 1 National recommendations

\begin{tabular}{|c|c|c|c|}
\hline Recommendation & $\begin{array}{c}\text { Online } \\
\text { publication date }\end{array}$ & $\begin{array}{c}\text { Print } \\
\text { publication date }\end{array}$ & Recommended screening practice \\
\hline${ }^{1}$ FDA Dear Healthcare Professional Letter & $7 / 12 / 2004$ & Online only & $\begin{array}{l}\text { Screen patients at high risk of HBV infection before initiation } \\
\text { of rituximab therapy. Closely monitor carriers of HBV for } \\
\text { clinical and laboratory signs of active HBV infection and for } \\
\text { signs of hepatitis during and for up to several months after } \\
\text { rituximab therapy. }\end{array}$ \\
\hline \multirow[t]{2}{*}{${ }^{2}$ AASLD } & $1 / 26 / 2007$ & $2 / 2007$ & $\begin{array}{l}\text { Screen patients at high risk for HBV infection prior to } \\
\text { immunosuppressive therapy. }\end{array}$ \\
\hline & & & Test with $\mathrm{HBsAg}$. \\
\hline \multirow[t]{2}{*}{${ }^{3} \mathrm{CDC}$} & 9/19/2008 & 9/19/2008 & Screen all patients prior to immunosuppressive therapies. \\
\hline & & & Test with $\mathrm{HBsAg}$, anti-HBC, and anti-HBs. \\
\hline \multirow[t]{2}{*}{${ }^{4}$ AASLD Update } & $7 / 28 / 2009$ & 9/2009 & $\begin{array}{l}\text { Screen patients at high risk for HBV infection prior to } \\
\text { immunosuppressive therapy. }\end{array}$ \\
\hline & & & Test with $\mathrm{HBsAg}$ and anti-HBc. \\
\hline \multirow[t]{2}{*}{${ }^{5} \mathrm{NCCN}$} & $8 / 28 / 2009$ & Online only & $\begin{array}{l}\text { Screen cancer patients with lymphoid malignancies, } \\
\text { patients who have spent significant time in HBV-endemic } \\
\text { areas or have risk factors for HBV infection, and patients } \\
\text { anticipating intensive immunosuppressive therapy. }\end{array}$ \\
\hline & & & Test with $\mathrm{HBsAg}$, anti-HBc, and anti-HBs. \\
\hline \multirow[t]{2}{*}{${ }^{6} \mathrm{IOM}$} & $1 / 11 / 2010$ & $1 / 11 / 2010$ & Screen patients with HBV risk factors. \\
\hline & & & Test with HBsAg. \\
\hline \multirow[t]{2}{*}{${ }^{7} \mathrm{ASCO}$} & $6 / 1 / 2010$ & $7 / 1 / 2010$ & $\begin{array}{l}\text { Screen cancer patients at high risk for HBV infection or } \\
\text { anticipating highly immunosuppressive therapy such } \\
\text { as stem cell transplantation or rituximab therapy. }\end{array}$ \\
\hline & & & Test with $\mathrm{HBsAg}$ and in some cases also with anti-HBc. \\
\hline
\end{tabular}

Abbreviations: AASLD American Association for the Study of Liver Diseases, ASCO American Society of Clinical Oncology, CDC Centers for Disease Control and Prevention, FDA Food and Drug Administration, IOM Institute of Medicine, NCCN National Comprehensive Cancer Network, HBsAg Hepatitis B surface antigen, anti-HBC Antibody to hepatitis B core antibody, anti-HBs Antibody to hepatitis B surface antigen.

response rates (5-63\%). Furthermore, screening practices reported in these studies may not reflect actual screening practices.

We previously found that only $17 \%$ of patients treated at a US cancer center from 2004 through 2007 were screened for HBV infection before chemotherapy [14]. The purpose of this study was to update our previous study by determining HBV screening rates at the same cancer center from 2004 through 2011 and to examine the possible influence of national recommendations published between 2004 and 2010 on HBV screening rates over time.

\section{Methods}

\section{Data sources}

We conducted a retrospective cohort study of adults with newly diagnosed cancer who registered at The University of Texas MD Anderson Cancer Center between January 1, 2004, and April 30, 2011, and received chemotherapy. This study was approved by the MD Anderson Institutional Review Board. We merged patient data from 4 institutional sources:
1. Tumor Registry: patient demographics, including birthplace, and cancer type (hematologic malignancies vs. solid tumors); primary liver cancer was excluded because of the etiologic relationship between HBV and hepatocellular carcinoma. At MD Anderson, patient's race/ethnicity can be ascertained based on self-reporting, reporting by the referring clinic, or assignment by administrative staff. We categorized race/ethnicity as White, Black, Hispanic, Asian, or Other. Birthplace in a region of moderate to high prevalence of $\mathrm{HBV}$ infection was considered a risk factor for HBV infection [3].

2. Pharmacy Informatics: chemotherapy drugs and dates administered. Chemotherapy was classified according to American Cancer Society classification [15]. We excluded oral chemotherapy because we could not validate medication dispensing dates. We excluded patients in therapeutic clinical trials since some clinical trials excluded patients with liver disease or hepatitis and screening for HBV was often dictated by the protocol and not reflective of the investigators' decision. 
3. Patient Accounts: ICD-9 codes corresponding to risk factors for HBV infection (see Table 2) anytime before the end of the screening period (defined below).

4. Laboratory Informatics: test dates and results for hepatitis B surface antigen (HBsAg), antibody to hepatitis B core antibody (anti-HBc), alanine aminotransferase, total bilirubin, and HBV DNA.

\section{HBV screening and infection}

Screening was defined as having both HBsAg and anti$\mathrm{HBc}$ tests ordered in the period from 2 months before the first administration of chemotherapy until the second administration of chemotherapy. MD Anderson has no official policy recommending prechemotherapy HBV screening. Positive findings on both HBsAg and anti$\mathrm{HBc}$ tests were considered to indicate chronic $\mathrm{HBV}$ infection. Negative HBsAg test but positive anti-HBc test were considered to indicate occult $\mathrm{HBV}$ infection or convalescence after previous infection. Unfortunately, antibody to hepatitis B surface antigen (anti-HBs) test, which is positive in convalescence and negative in occult disease, was ordered in only $1 \%$ of patients.

\section{Three time periods}

We used dates of the publication of national HBV recommendations to create 3 time intervals and categorized patients in these intervals according to date of first chemotherapy administration. We used 90 days after publication of recommendations as cut-off dates to allow adequate time for dissemination and potential change in practice patterns.

- Period 1: January 1, 2004, through December 18, 2008 (includes publication of Food and Drug Administration [FDA] letter [1] and 2007 American Association for the Study of Liver Diseases [AASLD] [2] recommendation).

- Period 2: December 19, 2008, through September 30, 2010 (includes publication of Centers for Disease Control and Prevention [CDC], [3] 2009 AASLD, [4] National Comprehensive Cancer Network [NCCN], [5] Institute of Medicine [IOM] [6] recommendations, and American Society of Clinical Oncology [ASCO] provisional clinical opinion [PCO] [7]).

- Period 3: October 1, 2010, through April 30, 2011 (after publication of above recommendations).

\section{Statistical methods}

We calculated screening prevalence for each time period and tested for an increase in screening across the 3 periods using Cochran-Armitage trend tests. We compared characteristics of screened and unscreened patients using Pearson's chi-square tests for categorical variables and Student's $t$-test for continuous variables. We calculated screening rate per quarter and determined the rate of change of screening prevalence per quarter by cancer type and time period using regression analysis. Our main outcome variable was screening using HBsAg and anti$\mathrm{HBc}$ tests. Independent variables included age, gender, race/ethnicity, US residency, having an HBV risk factor, cancer type, rituximab therapy, and date of first chemotherapy administration. We used 2 logistic regression models to identify predictors of screening, one for patients with solid tumors and one for patients with hematologic malignancies. We used backward elimination to select final models with a criterion of $P>0.05$ for exclusion. Hosmer and Lemeshow goodness-of-fit tests were used to evaluate model fit. We determined the proportion of positive test results among screened patients and compared the rates of either a positive $\mathrm{HBsAg}$ test or a positive anti-HBc test result across the 3 time periods using Pearson's chi-square test. We used SAS software, version 9.2 (SAS Institute, Cary, North Carolina), for statistical analyses.

\section{Results}

During the study period, 141,877 new patients were registered at MD Anderson (Figure 1), of whom 18,688 (13.2\%) received chemotherapy at MD Anderson. Overall, $3020(16.2 \%)$ of the patients who received chemotherapy were screened for $\mathrm{HBV}$ infection around the onset of chemotherapy.

The prevalence of HBV screening was approximately $4 \%$ $(581 / 15,031)$ among patients with solid tumors and nearly $67 \%$ (2439/3657) among patients with hematologic malignancies. Nearly 29\% (5391) of all patients had a risk factor for $\mathrm{HBV}$ infection, and less than 19\% of these patients (1016) were screened. Over 10\% (1977) of all patients received rituximab, and nearly $69 \%$ of these patients (1360) were screened. About 15\% of the Asian patients and 12\% of the Black patients were screened compared to nearly $17 \%$ of the White patients (Table 2).

The prevalence of HBV screening increased slightly across the 3 time periods, from $14.8 \%$ in period 1 to $18.2 \%$ in period 2 and $19.9 \%$ in period $3(P<0.001)$ (Table 3). For patients with known risk factors for HBV infection, screening prevalence increased over the 3 periods. For patients who received rituximab, screening prevalence increased between periods 1 and 2 and then decreased slightly in period 3. For Asian patients, screening prevalence did not change significantly over the 3 periods; for Black patients, screening prevalence increased over the 3 periods (Table 3 ).

Screening was almost always performed with both HBsAg and anti-HBc. Rates of use of the HBsAg test alone were $0.8 \%$ in period $1,0.4 \%$ in period 2 , and $0.9 \%$ 
Table 2 Characteristics of the study population by screening status

\begin{tabular}{|c|c|c|c|c|}
\hline Characteristic & $\begin{array}{l}\text { All patients } \\
\begin{array}{r}(\mathrm{N}=18,688) \\
\text { No. }(\%)^{\mathrm{a}}\end{array}\end{array}$ & $\begin{array}{r}\text { Screened patients } \\
\qquad \begin{array}{r}(\mathrm{N}=3020) \\
\text { No. }(\%)^{\mathrm{b}}\end{array}\end{array}$ & $\begin{array}{r}\text { Unscreened patients } \\
\qquad \begin{array}{r}(\mathrm{N}=15668) \\
\text { No. }(\%)^{\mathrm{b}}\end{array}\end{array}$ & $P$ value \\
\hline Age, years, mean (SD) & $55.0(13.5)$ & $52.5(15.4)$ & $55.5(13.0)$ & $<0.0001$ \\
\hline Sex & & & & $<0.0001$ \\
\hline Female & $10,608(56.8)$ & $1305(12.3)$ & $9303(87.7)$ & \\
\hline Male & $8080(43.2)$ & $1715(21.2)$ & $6365(78.8)$ & \\
\hline Race/ethnicity & & & & $<0.0001$ \\
\hline White & $13,168(70.5)$ & $2168(16.5)$ & $11000(83.5)$ & \\
\hline Hispanic & $2319(12.5)$ & $402(17.3)$ & $1917(82.7)$ & \\
\hline Black & $2092(11.2)$ & $247(11.8)$ & $1845(88.2)$ & \\
\hline Asian & $508(2.7)$ & $76(15.0)$ & $432(85.0)$ & \\
\hline Other & $601(3.2)$ & $127(21.1)$ & $474(78.9)$ & \\
\hline US residence & 18,090 (96.8) & $2896(16.0)$ & $15194(84.0)$ & 0.002 \\
\hline HBV risk factor ${ }^{\mathrm{c}, \mathrm{d}}$ & $5391(28.8)$ & $1016(18.8)$ & $4375(81.2)$ & $<0.0001$ \\
\hline Birthplace & $1286(6.9)$ & $220(17.1)$ & $1066(82.9)$ & \\
\hline Abnormal liver function & $368(2.0)$ & $170(46.2)$ & $198(53.8)$ & \\
\hline Hepatitis (not specified) & $173(0.9)$ & $90(52.0)$ & $83(48.0)$ & \\
\hline Hepatitis C & $213(1.1)$ & $104(48.8)$ & $109(51.2)$ & \\
\hline Other liver conditions & $3821(20.4)$ & $610(16.0)$ & $3211(84.0)$ & \\
\hline HIV & $70(0.4)$ & $39(55.7)$ & $31(44.3)$ & \\
\hline Drug abuse & $39(0.2)$ & $15(38.5)$ & $24(61.5)$ & \\
\hline Sexually transmitted disease & $106(0.6)$ & $36(34.0)$ & $70(66.0)$ & \\
\hline History of HBV infection ${ }^{e}$ & $78(0.4)$ & $20(25.6)$ & $58(74.4)$ & 0.02 \\
\hline Cancer type & & & & $<0.0001$ \\
\hline Solid tumor ${ }^{f}$ & $15,031(80.4)$ & $581(3.9)$ & $14450(96.1)$ & \\
\hline Hematologic malignancy & $3657(19.6)$ & $2439(66.7)$ & 1218 (33.3) & \\
\hline Chemotherapy type & & & & $<0.0001$ \\
\hline Rituximab & $1977(10.6)$ & $1360(68.8)$ & $617(31.2)$ & \\
\hline Non-rituximab & $16,711(89.4)$ & $1660(9.9)$ & $15051(90.1)$ & \\
\hline
\end{tabular}

Abbreviations: HBV hepatitis B virus, HIV human immunodeficiency virus, SD standard deviation, US United States.

${ }^{a}$ The percentages represent column percentages (denominator equal to total number of patients in the study, 18,688). For example, 56.8\% (10,608/18,688) of the patients in the study were women.

${ }^{\mathrm{b}}$ The percentages represent row percentages (denominator equal to total number of patients with the given characteristic). For example, 12.3\% (1305/10,608) of the females were screened for HBV infection while $87.7 \%(9303 / 10,608)$ were not.

'Patients born in countries with moderate to high prevalence of HBV infection according to the Centers for Disease Control and Prevention ${ }^{3}$ or at least 1 of the following ICD-9 diagnosis codes any time before chemotherapy were considered to have a risk factor for HBV infection:

(i) abnormal liver function (codes 794.8);

(ii) hepatitis, not specific (codes $070,070.4,070.49,070.5,070.59,070.6,070.9,571.4,571.40,571.41,571.42,571.49,573.1,573.2,573.3$, v02.6, v02.60, and v02.69);

(iii) other liver conditions (codes 571, 571.0, 571.2, 571.3, 571.5, 571.6, 571.8, 571.9, 572, 572.0, 572.2, 572.8, 573, 573.8, 573.9, 782.4, 789.1, and 794.8);

(iv) hepatitis $C$ (codes 070.41, 070.44, 070.51, 070.54, 070.7, 070.70, 070.71, and v02.62);

(v) HIV (codes 042, 042.0, 042.1, 042.2, 043, 043.0, 043.1, 043.2, 043.3, 044.0, 044.9, 079.53, 795.71, 795.8, v08, and v65.44);

(vi) drug abuse (codes 305.9, 305.90, 305.91, 305.92, 305.93);

(vii) sexually transmitted disease (codes 054.1, 054.10, 054.19, 078, 078.10, 078.11, 078.19, 078.8, 078.88, 079.8, 079.88, 079.9, 079.98, 091, 091.0, 091.1, 091.2, 091.3,

091.4, 091.5, 091.6, 091.69, 091.7, 091.8, 091.89, 091.9, 092, 092.0, 092.9, 093, 093.8, 093.89, 093.9, 094, 094.3, 094.8, 094.89, 094.9, 095, 095.1, 095.3, 095.4, 095.5,

095.6, 095.7, 095.8, 095.9, 096, 097, 097.0, 097.1, 097.9, 099.41, 099.50, 099.51, 099.52, 099.53, 099.54, 099.55, 099.56, 099.59, 483.1, v02.7, v73.8).

${ }^{\mathrm{d}}$ Sum of patient numbers in the individual risk factor categories exceeds total number of patients with risk factors $(\mathrm{n}=5391)$ since some patients had more than 1 HBV risk factor.

'We considered patients to have a history of HBV infection if they had an ICD-9 code for HBV infection $(0.70 .22,0.70 .23,0.70 .30,0.70 .32,0.70 .33,0.70 .44,0.70 .51$, $0.70 .54,0.70 .70$, v02.61, v02.62) either 1) before HBV screening test among patients who were screened, or 2) before the second chemotherapy administration among patients who did not have HBV screening.

${ }^{f}$ Excludes primary liver cancer. 


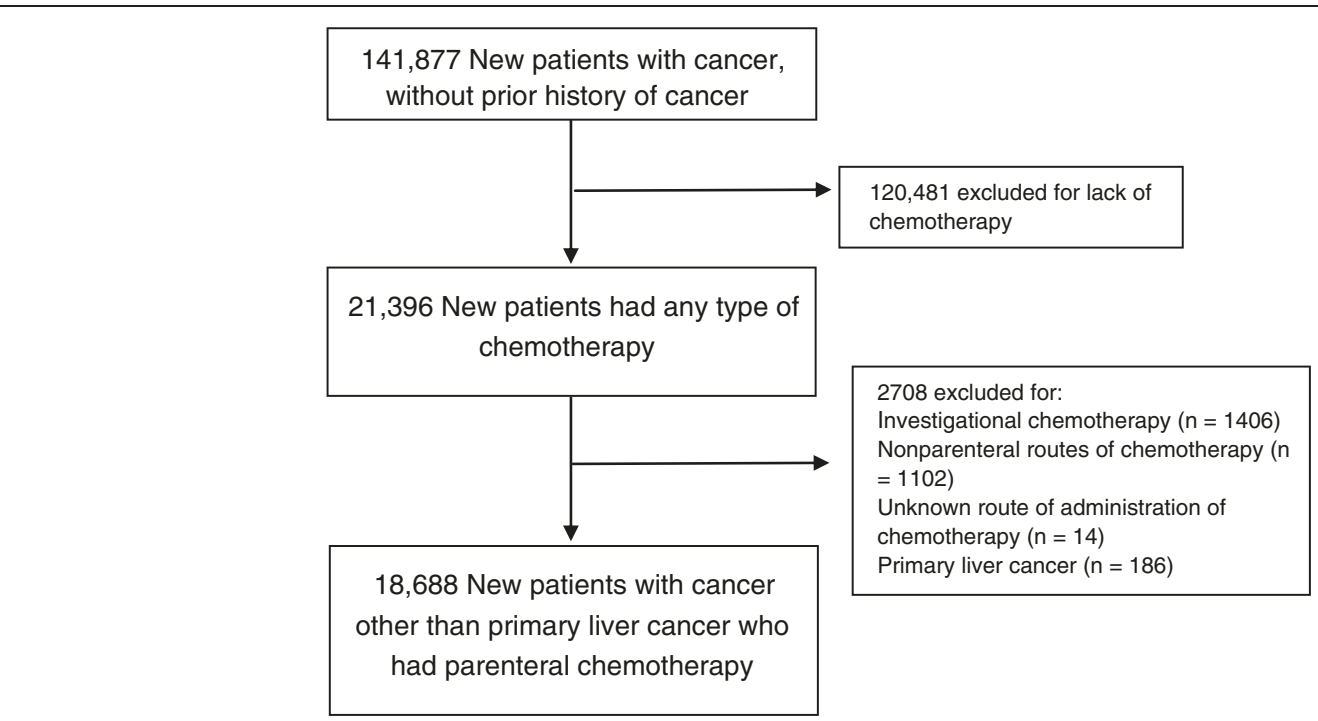

Figure 1 Study patient population. Flow diagram for study patients showing the exclusion of patients who did not have chemotherapy, had investigational chemotherapy, or non-parenteral routes of chemotherapy. Patients with primary liver cancer were also excluded.

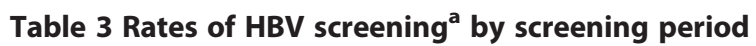

\begin{tabular}{|c|c|c|c|c|c|c|c|}
\hline \multirow[t]{2}{*}{ Characteristic } & \multicolumn{2}{|r|}{ Period $1^{b}$} & \multicolumn{2}{|r|}{ Period $2^{c}$} & \multicolumn{2}{|r|}{ Period $3^{d}$} & \multirow[t]{2}{*}{$P$ value } \\
\hline & $\begin{array}{l}\text { All patients } \\
(\mathrm{N}=11,833)\end{array}$ & $\begin{array}{r}\text { Screened patients } \\
(\mathrm{N}=1754)\end{array}$ & $\begin{array}{r}\text { All patients } \\
(\mathrm{N}=5703)\end{array}$ & $\begin{array}{r}\text { Screened patients } \\
(\mathrm{N}=1037)\end{array}$ & $\begin{array}{r}\text { All patients } \\
(\mathrm{N}=1152)\end{array}$ & $\begin{array}{r}\text { Screened patients } \\
(\mathrm{N}=229)\end{array}$ & \\
\hline Age, years, mean (SD) & $54.8(13.6)$ & $51.6(15.6)$ & $55.1(13.4)$ & $53.1(15.2)$ & $56.4(13.1)$ & $56.1(14.7)$ & 0.0001 \\
\hline \multicolumn{8}{|l|}{ Sex, no. (\%) } \\
\hline Female & 6702 & $731(10.9)$ & 3263 & $464(14.2) 14.22$ & 643 & $110(17.1) 17.11$ & $<0.0001$ \\
\hline Male & 5131 & $1023(20.0) 19.94$ & 2440 & 573 (23.5) 23.48 & 509 & 119 (23.4) 23.38 & 0.0003 \\
\hline \multicolumn{8}{|l|}{ Race/ethnicity, no. (\%) } \\
\hline White & 8464 & $1269(15.0)$ & 3895 & $738(19.0)$ & 809 & $161(19.9)$ & $<0.0001$ \\
\hline Hispanic & 1441 & $218(15.1)$ & 747 & $152(20.4)$ & 131 & $32(24.0)$ & $<0.0001$ \\
\hline Black & 1301 & $143(11.0)$ & 654 & $83(12.7)$ & 137 & $21(15.3)$ & 0.04 \\
\hline Asian & 311 & $45(14.5)$ & 158 & $23(14.6)$ & 39 & $8(19.4)$ & 0.23 \\
\hline Other & 316 & $79(25.0)$ & 249 & $41(16.5)$ & 36 & $7(20.5)$ & 0.02 \\
\hline US residence, no. (\%) & 11,480 & 1675 (14.6) & 5499 & $997(18.1)$ & 1111 & $224(20.0)$ & $<0.0001$ \\
\hline HBV risk factor, no. (\%) & 3412 & $572(16.8)$ & 1668 & $356(21.3)$ & 311 & $88(28.3)$ & $<0.0001$ \\
\hline Cancer type, no. (\%) & & & & & & & $<0.0001$ \\
\hline Solid tumor ${ }^{f}$ & 9521 & $326(3.4)$ & 4602 & $208(4.5)$ & 908 & $47(5.2)$ & $<0.0001$ \\
\hline Hematologic malignancy & 2312 & $1428(61.8)$ & 1101 & 829 (75.3) & 244 & $182(74.6)$ & $<0.0001$ \\
\hline \multicolumn{8}{|l|}{ Chemotherapy } \\
\hline \multicolumn{8}{|l|}{ Type, n (\%) } \\
\hline Rituximab & 1244 & $785(63.1)$ & 606 & $481(79.4)$ & 127 & $94(74.0)$ & $<0.0001$ \\
\hline Non-rituximab & 10,589 & $969(9.4)$ & 5097 & $556(10.9)$ & 1025 & $135(13.2)$ & $<0.0001$ \\
\hline
\end{tabular}

Abbreviations: $H B V$ hepatitis B virus, SD standard deviation, US United States.

${ }^{a} \mathrm{HBV}$ screening means that both hepatitis B surface antigen ( $\mathrm{HBsAg}$ ) test and antibody to hepatitis B core antigen (anti-HBC) test were ordered.

${ }^{b}$ First chemotherapy administration from $1 / 1 / 04$ through $12 / 18 / 2008$.

${ }^{c}$ First chemotherapy administration from 12/19/2008 through 9/30/2010.

${ }^{\mathrm{d}}$ First chemotherapy administration from 10/1/2010 through 4/30/11.

${ }^{\text {e}}$ Cochran-Armitage trend test compares screened patients vs. unscreened patients, over the 3 time periods.

${ }^{f}$ Excludes primary liver cancer. 
in period $3(P=0.06)$. Among the 3020 screened patients, 252 (8.3\%) had a positive result for either HBsAg or anti-HBc test. Specifically, 31 (1.0\%) had positive results on both HBsAg and anti-HBc tests, 218 (7.2\%) had a negative $\mathrm{HBsAg}$ test and a positive anti-HBc test, and $3(0.1 \%)$ had a positive HBsAg but negative anti$\mathrm{HBc}$. Assuming that unscreened patients had negative tests, the proportions of patients with a positive result on either $\mathrm{HBsAg}$ or anti-HBc testing among all patients who received chemotherapy in periods 1,2 , and 3 were $1.4 \%(169 / 11,833), 1.5 \%(84 / 5703)$, and $1.7 \%(19 / 1152)$, respectively $(P<0.0001)$.

\section{Solid tumors}

Among patients with solid tumors, screening rates for periods 1,2 , and 3 , respectively, were as follows: breast: $2.1 \%$, $2.2 \%, 5.8 \%(P=0.01)$; lung: $1.1 \%, 2.9 \%, 2.9 \%(P=0.009)$; colon: $3.5 \%, 4.6 \%, 3.4 \%(P=0.30)$; and prostate: $2.8 \%, 2.9 \%$, $2.8 \%(P=0.37)$. The odds of HBV screening were increased by $30 \%$ and $70 \%$ for patients who had chemotherapy in periods 2 and 3, respectively, compared to period 1 (Table 4). Other significant predictors of higher rate of HBV screening were younger age, male gender, US residence, having at least $1 \mathrm{HBV}$ risk factor, and planned rituximab therapy. HBV screening was performed in $64.4 \%$ of patients with and in $3.2 \%$ without rituximab in their chemotherapy regimen.

\section{Hematologic malignancies}

Among patients with hematologic malignancies, the screening rate increased during period 1 by $1 \%$ per quarter and then stabilized for periods 2 and 3 (Figure 2). This pattern was seen in lymphoma patients $(63.5 \%, 81.3 \%, 81.3 \%$ for periods 1,2 , and 3 , respectively; $P \leq 0.001$ ) and acute leukemia patients $(75.2 \%, 88.9 \%, 89.1 \%$ for periods 1,2 , and 3 , respectively; $P \leq 0.001)$. The odds of screening were nearly twice as high for patients who had chemotherapy in period 2 as for patients who had chemotherapy in period 1 (Table 4). No incremental effect was observed after publication of national recommendations. Other significant predictors of screening were younger age, having at least $1 \mathrm{HBV}$ risk factor, and planned rituximab therapy. HBV screening was performed in $69.2 \%$ of patients with and $64.2 \%$ of patients without rituximab in their chemotherapy regimen. Black race was associated with a lower screening rate.

\section{Discussion}

We found that the HBV screening prevalence among new patients receiving chemotherapy at a large US cancer center over the period 2004-2011 was only $16.2 \%$. Of particular concern, the prevalence of HBV screening was low $(<19 \%)$ even for patients with known HBV risk factors. Over $66 \%$ of patients with hematologic malignancies but less than $4 \%$ of those with solid tumors were screened. Predictors of HBV screening included having an HBV risk factor and planned rituximab therapy. Interestingly, race/ethnicity was associated with the likelihood of HBV screening for patients with hematologic malignancies but not with solid tumors. Importantly, HBV screening prevalence increased over time and higher rates were sustained after publication of national HBV screening recommendations. In this study of provider-driven screening, $8.3 \%$ of screened patients had a positive HBsAg or anti-HBc test result. The proportion of patients who tested positive for HBV infection increased by over $20 \%$ from period 1 to period 3 , suggesting that increased screening may lead to increased identification of patients with HBV infection.

The finding that most patients with hematologic malignancies were screened for HBV infection whereas most patients with known HBV risk factors were not, together with the finding that most patients who received rituximab, a known risk factor for reactivation, were screened, suggests that oncologists are more aware of the risk factors for HBV reactivation than they are of the risk factors for HBV infection. This may have reflected the effect of the FDA letters, package inserts, and recommendations as well as publications in the oncology literature about HBV reactivation associated with rituximab treatment. These data indicate that future educational efforts on risk factors for $\mathrm{HBV}$ infection for oncology providers might increase HBV screening.

For patients with hematologic malignancies, the prevalence of HBV screening increased dramatically during period 1, which included the FDA letter. This increase may be related to the high risk (nearly 50\%) of reactivation [16] and frequent reports of reactivation among patients with hematologic malignancies [17-19] and to the frequent reports of reactivation among patients receiving rituximab [20-24]. The further increase in screening prevalence during periods 2 and 3 was likely due to the emphasis in national recommendations on the risk of HBV reactivation in these patients.

For patients with solid tumors, odds of screening increased over all 3 time periods; however, the vast majority (96\%) of patients were not screened. The low rate of $\mathrm{HBV}$ screening among patients with solid tumors is concerning because of previous reports of reactivation and related delays in chemotherapy and increases in mortality in patients with breast cancer [25-27], glioblastoma [28], germ cell tumors [27], and cancers of the lung, colon, and stomach [27,29-31]. Indeed, the risk of reactivation among patients with solid tumors is estimated to be approximately 15\% [27]; however, these data were derived in an HBVendemic area. Therefore, studies are needed to define risks and to determine predictors of reactivation for US patients with solid tumors. 
Table 4 Predictors of HBV screening ${ }^{\text {a by cancer type }}$

\begin{tabular}{|c|c|c|c|c|c|c|c|c|c|c|}
\hline \multirow[t]{3}{*}{ Predictor } & \multicolumn{5}{|c|}{ Hematologic malignancy $(\mathrm{N}=3657)$} & \multicolumn{5}{|c|}{ Solid tumorb $(N=15,031)$} \\
\hline & \multirow{2}{*}{$\begin{array}{r}\text { Screened } \\
(\mathrm{N}=2439)(66.7 \%)\end{array}$} & \multicolumn{2}{|c|}{$\begin{array}{r}\text { Univariate } \\
\text { logistic regression }\end{array}$} & \multicolumn{2}{|c|}{$\begin{array}{r}\text { Multiple logistic } \\
\text { regression OR }\end{array}$} & \multirow{2}{*}{$\begin{array}{r}\text { Screened } \\
(\mathrm{N}=581)(3.9 \%)\end{array}$} & \multicolumn{2}{|c|}{$\begin{array}{r}\text { Univariate } \\
\text { logistic regression }\end{array}$} & \multicolumn{2}{|c|}{$\begin{array}{r}\text { Multiple } \\
\text { logistic regression }\end{array}$} \\
\hline & & OR $(95 \% \mathrm{Cl})$ & $P$ value & $(95 \% \mathrm{Cl})$ & $P$ value & & OR $(95 \% \mathrm{Cl})$ & $P$ value & OR $(95 \% \mathrm{Cl})$ & $P$ value \\
\hline Age, years, mean (SD) & $52.5(15.5)$ & $0.99(0.99-1.0)$ & 0.005 & $0.99(0.98-0.99)$ & 0.0001 & $52.4(15.0)$ & $0.98(0.98-0.99)$ & $<0.0001$ & $0.98(0.97-0.98)$ & $<0.0001$ \\
\hline \multicolumn{11}{|l|}{ Sex, no. (\%) } \\
\hline Male & 1418/2133 (66.5) & Ref. & - & - & - & 297/5947 (5.0) & Ref. & - & Ref. & - \\
\hline Female & 1021/1524 (67.0) & $1.0(0.89-1.2)$ & 0.74 & - & - & 284/9084 (3.1) & $0.61(0.52-0.73)$ & $<0.0001$ & $0.58(0.49-0.70)$ & $<0.0001$ \\
\hline \multicolumn{11}{|l|}{ Race/ethnicity, no. (\%) } \\
\hline White & $1776 / 2645(67.2)$ & Ref. & - & Ref. & - & $392 / 10,523(3.7)$ & Ref. & - & - & - \\
\hline Hispanic & $324 / 486(66.7)$ & $0.98(0.80-1.2)$ & 0.84 & $0.92(0.75-1.1)$ & 0.45 & 78/1833 (4.3) & $1.1(0.90-1.5)$ & 0.27 & - & - \\
\hline Black & 196/333 (58.9) & $0.70(0.56-0.88)$ & 0.003 & $0.69(0.55-0.88)$ & 0.002 & $51 / 1759(2.9)$ & $0.77(0.57-1.0)$ & 0.09 & - & - \\
\hline Asian & $41 / 50(82.0)$ & $2.2(1.1-4.6)$ & 0.03 & $2.0(0.98-4.3)$ & 0.06 & 35/458 (7.6) & $2.1(1.5-3.1)$ & $<0.0001$ & - & - \\
\hline Other & 102/143 (71.3) & $1.2(0.8-1.8)$ & 0.23 & $1.0(0.72-1.6)$ & 0.79 & 25/458 (5.5) & $1.5(0.98-2.3)$ & 0.06 & - & - \\
\hline \multicolumn{11}{|l|}{ Residence, no. (\%) } \\
\hline US & 2332/3510 (66.4) & Ref. & - & - & - & $564 / 14,580(3.9)$ & Ref. & - & Ref. & - \\
\hline Outside US & 107/147(72.8) & $1.4(0.93-2.0)$ & 0.11 & - & - & 17/451 (3.8) & $0.97(0.59-1.6)$ & 0.92 & $0.51(0.30-0.90)$ & 0.02 \\
\hline \multicolumn{11}{|l|}{ HBV risk factor, no. (\%) } \\
\hline No & 1683/2603 (64.7) & Ref. & - & Ref. & - & $321 / 10,694(3.0)$ & Ref. & - & Ref. & \\
\hline Yes & 756/1054 (71.7) & $1.4(1.2-1.6)$ & $<0.0001$ & $1.3(1.1-1.5)$ & 0.001 & 260/4337 (6.0) & $2.1(1.7-2.4)$ & $<0.0001$ & $2.5(2.1-3.0)$ & $<0.0001$ \\
\hline \multicolumn{11}{|c|}{ Chemotherapy type, no. (\%) } \\
\hline Non-rituximab & 1191/1854 (64.2) & Ref. & - & Ref. & - & $469 / 14,857(3.2)$ & Ref. & - & Ref. & - \\
\hline Rituximab & 1248/1803 (69.2) & $1.2(1.1-1.4)$ & 0.001 & $1.3(1.2-1.5)$ & $<0.0001$ & $112 / 174(64.4)$ & $55.4(40.1-76.6)$ & $<0.0001$ & $62.0(44.1-87.0)$ & $<0.0001$ \\
\hline \multicolumn{11}{|c|}{ Timing of first chemotherapy ${ }^{c}$} \\
\hline Period 1 & 1428/2312 (61.8) & Ref. & - & Ref. & - & 326/9521 (3.4) & Ref. & - & Ref. & - \\
\hline Period 2 & 829/1101 (75.3) & $1.9(1.6-2.2)$ & $<0.0001$ & $2.0(1.6-2.3)$ & $<0.0001$ & 208/4602 (4.5) & $1.3(1.1-1.6)$ & 0.001 & $1.3(1.1-1.6)$ & 0.003 \\
\hline Period 3 & 182/244 (74.6) & $1.8(1.4-2.4)$ & $<0.0001$ & $1.9(1.4-2.6)$ & $<0.0001$ & 47/908 (5.2) & $1.5(1.1-2.1)$ & 0.007 & $1.7(1.2-2.3)$ & 0.003 \\
\hline
\end{tabular}

Abbreviations: $H B V$ hepatitis B virus, OR odds ratio, $\mathrm{Cl}$ confidence interval, Ref., reference.

${ }^{a} \mathrm{HBV}$ screening means that both hepatitis B surface antigen (HBsAg) test and antibody to hepatitis B core antigen (anti-HBc) test were ordered.

${ }^{b}$ Excludes patients with primary liver cancer.
CPeriod 1: 1/1/04 through 12/18/2008; period 2, 12/19/2008 through 9/30/2010; period 3, 10/1/2010 through 4/30/11. 


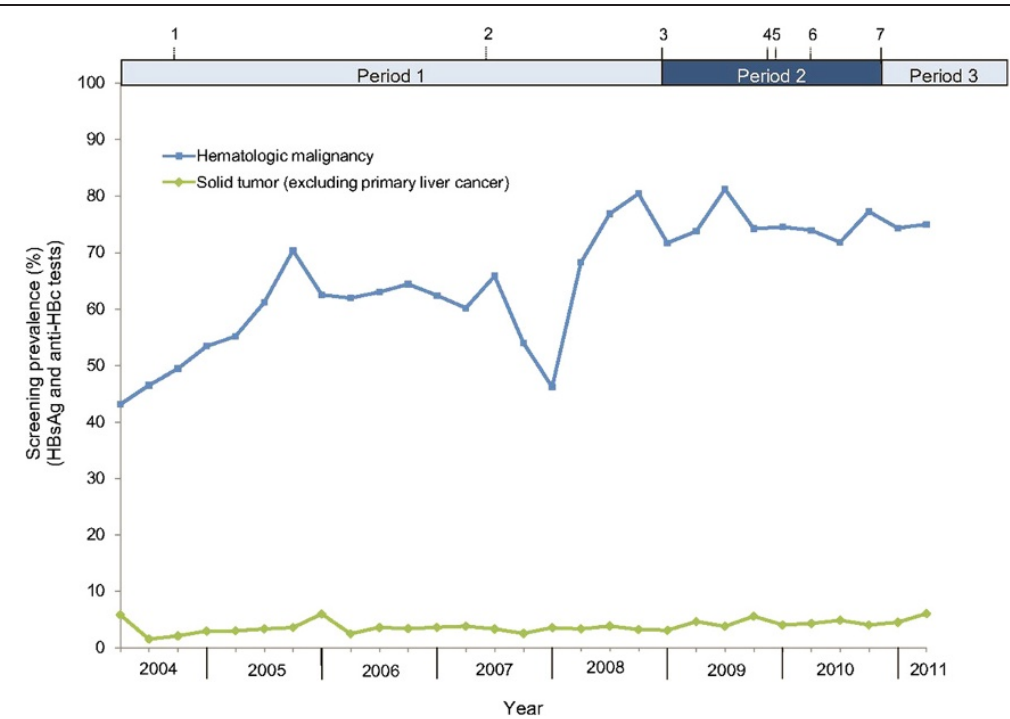

Figure 2 Trends in HBV Screening at MD Anderson Cancer, 2004-2011, in relation to publication of recommendations. HBV screening prevalence is shown for patients with hematologic malignancies (blue line) and solid tumors (green line). Data points indicate average screening prevalence per quarter (Q) of each year. Q1, Jan 1-Mar 31; Q2, Apr 1-Jun 30; Q3, Jul 1-Sept 30; Q4, Oct 1-Dec 31. Numbers at top of figure refer to publication of national recommendations and associated reference number, as follows: 1, US Food and Drug Administration; 2, American Association for the Study of Liver Diseases (2007); 3, Centers for Disease Control and Prevention; 4, American Association for the Study of Liver Diseases (2009); 5, National Comprehensive Cancer Network; 6, Institute of Medicine; and 7, American Society of Clinical Oncology.

Most of the national recommendations [1,2,4-7] call for prechemotherapy HBV screening in patients with high risk of HBV infection. Although the overall screening prevalence among patients with HBV risk factors was low, the prevalence increased over time, and having an HBV risk factor predicted screening. However, since previous studies have shown that screening based on risk factors alone would miss up to $45 \%$ to $65 \%$ of patients who actually had HBV infection, [32,33] future research is warranted to better understand the efficacy of risk-based screening.

Our study's screening rate is lower than that in previous studies, which have described rates of adherence to cancer-related guidelines ranging from $27 \%$ to $97 \%$, [34-41] although it is possible that our screening rates may have underestimated the actual rate since we could not verify HBV screening performed before registration at MD Anderson. Reasons for noncompliance with HBV screening guidelines may have included patient characteristics such as age [34,38] and stage of disease [34], physician attitudes towards guidelines [42], and education about guidelines [43]. One study [44] found that physicians' lack of awareness of and lack of agreement with guidelines were potential barriers to adherence. A previous study by In et al. [45] reported a higher variation in surgical cancer care when guidelines were based on low levels of evidence or expert opinion. Future research providing high levels of evidence will be necessary to improve adherence to HBV screening.
We found that rituximab was a predictor of screening for all patients, especially those with solid tumors. Rituximab is a monoclonal antibody against CD20+ that causes severe B-cell depletion $[46,47]$ and facilitates uncontrolled replication of HBV. However, besides rituximab, many other chemotherapy drugs [25-28,48-54] have been associated with HBV reactivation. Future studies focusing on mechanisms by which certain chemotherapy drugs may cause reactivation will help shape future evidence-based screening strategies.

Interestingly, whereas race/ethnicity did not predict HBV screening among patients with solid tumors, among patients with hematologic malignancies, Black patients had lower odds of screening than White patients. This is concerning because previous population-based studies have shown that the prevalence of HBV infection (current and past) is higher among Black than White adults (9.6\% vs. $2.3 \%, P<0.001)$ [55]. Perhaps physicians are unaware of the higher HBV risk in Black patients. We were surprised that Asian race did not predict HBV screening even though the prevalence of chronic HBV infection in this group may be as high as $20 \%$ [55-57]. Failure to screen Asian patients may have reflected lack of awareness by physicians of HBV risk factors [58,59]. In addition, we were surprised that patients with solid tumors who resided outside the US had lower odds of HBV screening, although it is possible that they were screened in their home countries.

We found substantial numbers of patients who had a negative $\mathrm{HBsAg}$ test result but a positive anti- $\mathrm{HBc}$ test 
result. Such patients may have occult HBV infection, as underscored by the high risk (78\%) of HBV transmission in recipients transplanted with livers from donors with isolated anti-HBc positivity as compared to donors who were anti-HBc negative $(0.05 \%)$ [60]. It is possible that isolated anti-HBc may represent false-positive test result among populations with a low prevalence of $\mathrm{HBV}$ infection. However, reactivation has been reported in patients who are $\mathrm{HBsAg}$ negative but anti-HBc positive during chemotherapy particularly if the regimen includes rituximab [21,24,61]. The ASCO PCO [7] recommends anti$\mathrm{HBc}$ testing in some populations-e.g., patients with hematologic malignancies-since the risk of reactivation has been reported to be $10 \%$ among patients with hematologic malignancies with isolated anti-HBc [62]. The CDC recommends HBV screening using $3 \mathrm{HBV}$ serology tests. We found that anti-HBs was rarely tested during our study period.

The strengths of our study include the large and heterogeneous patient population and the focus on actual rather than recalled HBV screening practice. Previous survey studies estimated 38\%-80\% of physicians screen patients before chemotherapy [11-13]; however, those results may inaccurately describe screening patterns since surveys record self-reporting of screening practice and not actual screening of individual patients. Our examination of physicians' actual screening behavior at the level of individual patients avoided recall bias or subconscious attempts to report what should be done rather than what was actually done.

The main limitation of our study is its retrospective design and use of administrative databases, which prevented us from fully assessing HBV history and HBV risk factors. Patients may have received chemotherapy before their first chemotherapy administration at MD Anderson. Also, we excluded oral chemotherapy because we could not accurately access dispensing records outside of MD Anderson, but some oral chemotherapy could cause HBV. Patients' race/ethnicity was self-described or assigned by referring clinics and may be incorrect. Another limitation is that we were not able to accurately determine prevalence of reactivation since not all patients who received chemotherapy were screened for HBV infection. This single-institution experience may not be generalizable to other settings, and our data cannot be generalized to patients who receive care in clinical trials as such patients were excluded. We did not explore socioeconomic factors such as income and educational level because this information is not part of our institutional Tumor Registry database. Most of our patients at MD Anderson have health insurance, and these plans are expected to pay for HBV screening tests. Finally, the last time period in our study was relatively short, limiting our ability to assess the full impact of the national recommendations. Nevertheless, our study provides valuable data from a large US academic cancer center with no changes in institutional policies regarding HBV screening during the study period.

\section{Conclusions}

In conclusion, we found that the prevalence of $\mathrm{HBV}$ screening before chemotherapy among new patients receiving chemotherapy at a large US cancer center during 2004-2011 was only $16.2 \%$ overall but increased over time. The vast majority of patients with solid tumors, even those with risk factors for $\mathrm{HBV}$ infection, remained unscreened. Future research is needed to explore risks and predictors of reactivation with chemotherapy for US patients to develop evidence-based screening guidelines. Once these are available, educational efforts should be developed to increase oncology medical providers' awareness of the importance of HBV screening and prophylaxis to prevent reactivation due to chemotherapy.

\section{Competing interests}

The authors declare that they have no competing interests.

\section{Authors' contributions}

All authors contributed to the interpretation of data, to the critical revision of the manuscript for important intellectual content, and to the administrative, technical, and material support for this project. JPH was responsible for the conception and design of the study, acquisition of the data, and analysis and interpretation of data, drafting of the manuscript, and funding for the project. $\mathrm{HZ}$ performed the statistical analysis. MES-A contributed to the conception and design of the study as well as provided funding and supervision for the project. All authors read and approved the final manuscript.

\section{Acknowledgements}

Supported by the National Institutes of Health through MD Anderson's Cancer Center Support Grant, CA016672. Dr. Hwang is a recipient of National Cancer Institute grants K07 CA132955 and R21 CA167202. Dr. Suarez-Almazor has a Midcareer Investigator Award from the National Institute of Arthritis and Musculoskeletal and Skin Diseases (K24 AR053593).

We are grateful to the following individuals for their assistance with institutional databases: Mark Routbort (Laboratory Informatics); Sarah Taylor (Tumor Registry); Chun Feng (Pharmacy Informatics); Weiming Shi (Patient Accounts). We would also like to acknowledge Susan Lackey, MPH, and Angelic Castillo, General Internal Medicine, for administrative support; Shana Palla, MS, and Andrea Barbo, MS, Department of Biostatistics, for manuscript review; Laurissa Gann, MSLS, Research Medical Library, for assistance with literature review; and Stephanie Deming, BA, Department of Scientific Publications, for editing the manuscript.

\section{Author details}

${ }^{1}$ Department of General Internal Medicine, The University of Texas MD Anderson Cancer Center, 1515 Holcombe Blvd., Unit 1465, Houston, Texas 77030, USA. ${ }^{2}$ University of Michigan, Ann Arbor, Michigan, USA. ${ }^{3}$ Baylor College of Medicine, Houston, Texas, USA. ${ }^{4}$ Department of General Oncology, The University of Texas MD Anderson Cancer Center, Houston, Texas, USA.

Received: 21 February 2013 Accepted: 31 October 2013

Published: 9 November 2013

\section{References}

1. MedWatch safety information: Rituxan (rituximab) Oct 2004. http://www.fda gov/Safety/MedWatch/SafetyInformation/SafetyAlertsforHumanMedical Products/ucm166521.htm]. Access date: August 31, 2012.

2. Lok AS, McMahon BJ: Chronic hepatitis B. Hepatology 2007, 45(2):507-539. 
3. Weinbaum CM, Williams I, Mast EE, Wang SA, Finelli L, Wasley A, Neitzel SM, Ward JW: Recommendations for identification and public health management of persons with chronic hepatitis $B$ virus infection. MMWR Recomm Rep 2008, 57(RR-8):1-20.

4. Lok ASF, McMahon BJ: AASLD Practice Guideline Update: Chronic Hepatitis B: Update 2009. Available at: http://www.aasld.org/practiceguidelines/ Documents/Bookmarked\%20Practice\%20Guidelines/ Chronic_Hep_B_Update_2009\%208_24_2009.pdf Accessed November 7, 2013. (2009)

5. Practice guidelines in oncology: Prevention and treatment of cancer-related infections; 2009. http://www.nccn.org/professionals/physician_gls/pdf/ infections.pdf]. Access date: August 31, 2012.

6. Hepatitis and Liver Cancer: A National Strategy for Prevention and Control of Hepatitis B and C. [http://www.iom.edu/Reports/2010/Hepatitis-and-LiverCancer-A-National-Strategy-for-Prevention-and-Control-of-Hepatitis-Band-C/Report-Brief-Hepatitis-and-Liver-Cancer.aspx]. Access date: December 6, 2012.

7. Artz AS, Somerfield MR, Feld JJ, Giusti AF, Kramer BS, Sabichi AL, Zon RT, Wong SL: American Society of Clinical Oncology provisional clinical opinion: chronic hepatitis B virus infection screening in patients receiving cytotoxic chemotherapy for treatment of malignant diseases. J Clin Oncol 2010, 28(19):3199-3202.

8. European Association for the Study of the Liver: EASL Clinical Practice Guidelines: management of chronic hepatitis B. J Hepatol 2009, 50(2):227-242.

9. Liaw YF, Leung N, Kao JH, Piratvisuth T, Gane E, Han KH, Guan R, Lau GK, Locarnini S: Asian-Pacific consensus statement on the management of chronic hepatitis B: a 2008 update. Hepatol Int 2008, 2(3):263-283.

10. Loomba R, Rowley A, Wesley R, Liang TJ, Hoofnagle JH, Pucino F, Csako G: Systematic review: the effect of preventive lamivudine on hepatitis $B$ reactivation during chemotherapy. Ann Intern Med 2008, 148(7):519-528.

11. Khokhar OS, Farhadi A, McGrail L, Lewis JH: Oncologists and hepatitis B: a survey to determine current level of awareness and practice of antiviral prophylaxis to prevent reactivation. Chemotherapy 2009, 55(2):69-75.

12. Tran TT, Rakoski MO, Martin P, Poordad F: Screening for hepatitis B in chemotherapy patients: survey of current oncology practices. Aliment Pharmacol Ther 2010, 31(2):240-246.

13. Day FL, Link E, Thursky K, Rischin D: Current Hepatitis B Screening Practices and Clinical Experience of Reactivation in Patients Undergoing Chemotherapy for Solid Tumors: a Nationwide Survey of Medical Oncologists. J Oncol Pract 2011, 7(3):141-147.

14. Hwang J, Fisch M, Zhang H, Kallen M, Routbort M, Lal L, Vierling J, Suarez-Almazor M: Low rates of hepatitis $B$ virus screening at the onset of chemotherapy. J Oncol Pract 2012, 8(4):e32-e39.

15. American Cancer Society: Chemotherapy principles: An in-depth discussion of the techniques and its role in cancer treatment. [http://www.cancer.org/ treatment/treatmentsandsideeffects/treatmenttypes/chemotherapy/ chemotherapyprinciplesanin-depthdiscussionofthetechniquesandits roleintreatment/chemotherapy-principles-intro]. Access date: August 31, 2012.

16. Lok AS, Liang RH, Chiu EK, Wong KL, Chan TK, Todd D: Reactivation of hepatitis $B$ virus replication in patients receiving cytotoxic therapy. Report of a prospective study. Gastroenterology 1991, 100(1):182-188.

17. Aksoy S, Harputluoglu H, Kilickap S, Dede DS, Dizdar O, Altundag K, Barista I: Rituximab-related viral infections in lymphoma patients. Leuk Lymphoma 2007, 48(7):1307-1312.

18. Liang R: How I treat and monitor viral hepatitis B infection in patients receiving intensive immunosuppressive therapies or undergoing hematopoietic stem cell transplantation. Blood 2009, 113(14):3147-3153.

19. Tomblyn M, Chiller T, Einsele H, Gress R, Sepkowitz K, Storek J, Wingard JR, Young JA, Boeckh MJ: Guidelines for preventing infectious complications among hematopoietic cell transplant recipients: a global perspective. Preface. Bone Marrow Transplant 2009, 44(8):453-455.

20. Mendez-Navarro J, Corey KE, Zheng H, Barlow LL, Jang JY, Lin W, Zhao H, Shao R-X, McAfee SL, Chung RT: Hepatitis B screening, prophylaxis and re-activation in the era of rituximab-based chemotherapy. Liver Int 2011 , 31(3):330-339

21. Yeo W, Chan TC, Leung NW, Lam WY, Mo FK, Chu MT, Chan HL, Hui EP, Lei Kl, Mok TS, et al: Hepatitis B virus reactivation in lymphoma patients with prior resolved hepatitis B undergoing anticancer therapy with or without rituximab. J Clin Oncol 2009, 27(4):605-611.
22. Tsutsumi Y, Yamamoto Y, Tanaka J, Asaka M, Imamura M, Masauzi N: Prevention of hepatitis $B$ virus reactivation under rituximab therapy. Immunotherapy 2009, 1(6):1053-1061.

23. Villadolid J, Laplant KD, Markham MJ, Nelson DR, George TJ Jr: Hepatitis B reactivation and rituximab in the oncology practice. Oncologist 2010, 15(10):1113-1121.

24. Leung $C$, Tsoi E, Burns G, Sievert W: An argument for the universal prophylaxis of hepatitis $B$ infection in patients receiving rituximab: a 7-year institutional experience of hepatitis screening. Oncologist 2011, 16(5):579-584

25. Yeo W, Chan PKS, Hui P, Ho WM, Lam KC, Kwan WH, Zhong S, Johnson PJ: Hepatitis $B$ virus reactivation in breast cancer patients receiving cytotoxic chemotherapy: a prospective study. J Med Virol 2003, 70(4):553-561.

26. Yun J, Kim KH, Kang ES, Gwak GY, Choi MS, Lee JE, Nam SJ, Yang JH, Park YH, Ahn JS, et al: Prophylactic use of lamivudine for hepatitis B exacerbation in post-operative breast cancer patients receiving anthracyclinebased adjuvant chemotherapy. Br J Cancer 2011, 104(4):559-563.

27. Yeo W, Chan PK, Zhong S, Ho WM, Steinberg JL, Tam JS, Hui P, Leung NW, Zee $\mathrm{B}$, Johnson PJ: Frequency of hepatitis B virus reactivation in cancer patients undergoing cytotoxic chemotherapy: a prospective study of 626 patients with identification of risk factors. J Med Virol 2000, 62(3):299-307.

28. Grewal J, Dellinger CA, Yung WK: Fatal reactivation of hepatitis B with temozolomide. N Engl J Med 2007, 356(15):1591-1592.

29. Eren OO, Artac M, Boruban MC, Yavas O, Arslan U, Basaranoglu M: Chemotherapy-induced hepatitis $\mathrm{B}$ virus reactivation in $\mathrm{Hbs} \mathrm{Ag}$ positive cancer patients: a single center experience. Med Oncol 2009, 26(4):386-392.

30. Steinberg JL, Yeo W, Zhong S, Chan JY, Tam JS, Chan PK, Leung NW, Johnson PJ: Hepatitis B virus reactivation in patients undergoing cytotoxic chemotherapy for solid tumours: precore/core mutations may play an important role. J Med Virol 2000, 60(3):249-255.

31. Yeo $W$, Johnson PJ: Diagnosis, prevention and management of hepatitis $B$ virus reactivation during anticancer therapy. Hepatology 2006, 43(2):209-220.

32. Brook MG, Lever AM, Kelly D, Rutter D, Trompeter RS, Griffiths $P$, Thomas HC: Antenatal screening for hepatitis B is medically and economically effective in the prevention of vertical transmission: three years experience in a London hospital. Q J Med 1989, 71(264):313-317.

33. Centers for Disease Control and Prevention: Prevention of perinatal transmission of hepatitis $B$ virus: prenatal screening of all pregnant women for hepatitis B surface antigen. MMWR Morb Mortal Wkly Rep 1988, 37(22):341-346.

34. Eldin NS, Yasui Y, Scarfe A, Winget M: Adherence to treatment guidelines in stage II/III rectal cancer in Alberta, Canada. Clin Oncol (R Coll Radiol) 2012, 24(1):e9-e17.

35. Cheung WY, Pond GR, Rother M, Krzyzanowska MK, Swallow C, Brierley J, Kaizer L, Myers J, Hajra L, Siu LL: Adherence to surveillance guidelines after curative resection for stage II/III colorectal cancer. Clin Colorectal Cancer 2008, 7(3):191-196.

36. Landercasper J, Dietrich $L L$, Johnson JM: A breast center review of compliance with National Comprehensive Cancer Network Breast Cancer guidelines. Am J Surg 2006, 192(4):525-527.

37. Varga D, Wischnewsky M, Atassi Z, Wolters R, Geyer V, Strunz K, Kreienberg $R$, Woeckel A: Does guideline-adherent therapy improve the outcome for early-onset breast cancer patients? Oncology 2010, 78(3-4):189-195.

38. Chagpar R, Xing Y, Chiang YJ, Feig BW, Chang GJ, You YN, Cormier JN: Adherence to stage-specific treatment guidelines for patients with colon cancer. J Clin Oncol 2012, 30(9):972-979.

39. Salloum RG, Hornbrook MC, Fishman PA, Ritzwoller DP, O'Keeffe Rossetti $M C$, Elston Lafata J: Adherence to surveillance care guidelines after breast and colorectal cancer treatment with curative intent. Cancer 2012, 118:5644-5651.

40. Hakonsen GD, Strelec P, Campbell D, Hudson S, Loennechen T: Adherence to medication guideline criteria in cancer pain management. J Pain Symptom Manage 2009, 37(6):1006-1018.

41. Mertens WC, Higby DJ, Brown D, Parisi R, Fitzgerald J, Benjamin EM, Lindenauer PK: Improving the care of patients with regard to chemotherapy-induced nausea and emesis: the effect of feedback to clinicians on adherence to antiemetic prescribing guidelines. J Clin Oncol 2003, 21(7):1373-1378. 
42. Browman GP: Improving clinical practice guidelines for the 21st century. Attitudinal barriers and not technology are the main challenges. Int J Technol Assess Health Care 2000, 16(4):959-968.

43. Grunberg SM: Obstacles to the Implementation of antiemetic guidelines. J Natl Compr Canc Netw 2009, 7(5):601-605.

44. Cabana MD, Rand CS, Powe NR, Wu AW, Wilson MH, Abboud PA, Rubin HR: Why don't physicians follow clinical practice guidelines? A framework for improvement. J Am Med Assoc 1999, 282(15):1458-1465.

45. In H, Neville BA, Lipsitz SR, Corso KA, Weeks JC, Greenberg CC: The role of National Cancer Institute-designated cancer center status: observed variation in surgical care depends on the level of evidence. Ann Surg 2012, 255(5):890-895.

46. van der Kolk LE, Baars JW, Prins MH, van Oers MH: Rituximab treatment results in impaired secondary humoral immune responsiveness. Blood 2002, 100(6):2257-2259.

47. Osterborg A, Dyer MJ, Bunjes D, Pangalis GA, Bastion Y, Catovsky D, Mellstedt H: Phase II multicenter study of human CD52 antibody in previously treated chronic lymphocytic leukemia. European Study Group of CAMPATH-1H Treatment in Chronic Lymphocytic Leukemia. J Clin Oncol 1997, 15(4):1567-1574.

48. Aomatsu T, Komatsu H, Yoden A, Hosomi A, Miyazaki H, Sogo T, Inui A, Fujisawa T, Tamai H: Fulminant hepatitis B and acute hepatitis B due to intrafamilial transmission of HBV after chemotherapy for non-Hodgkin's lymphoma in an HBV carrier. Eur J Pediatr 2010, 169(2):167-171.

49. Cil T, Altintas A, Pasa S, Bayan K, Ozekinci T, Isikdogan A: Lamivudine for the prevention of hepatitis $B$ virus reactivation in hepatitis-B surface antigen (HBSAG) seropositive cancer patients undergoing cytotoxic chemotherapy. Leuk Lymphoma 2008, 49(5):939-947.

50. lannitto E, Minardi V, Calvaruso G, Mule A, Ammatuna E, Di Trapani R, Ferraro D, Abbadessa V, Craxi A, Di Stefano R: Hepatitis B virus reactivation and alemtuzumab therapy. Eur J Haematol 2005, 74(3):254-258.

51. Rago A, Ridola L, Lichtner M, Mecarocci S, Marocco R, Cenfra N, Belvisi V, Mastroianni CM, Cimino G: Hepatitis B reactivation despite entecavir prophylaxis in a patient with chronic lymphocytic leukaemia receiving bendamustine. J Antimicrob Chemother 2012, 67(2):510-511.

52. Cortelezzi A, Vigano M, Zilioli VR, Fantini NN, Pasquini MC, Deliliers GL, Colombo M, Lampertico P: Adefovir added to lamivudine for hepatitis $B$ recurrent infection in refractory B-cell chronic lymphocytic leukemia on prolonged therapy with Campath-1H. J Clin Virol 2006, 35(4):467-469.

53. Ikeda K, Shiga Y, Takahashi A, Kai T, Kimura H, Takeyama K, Noji H, Ogawa K, Nakamura A, Ohira $\mathrm{H}$, et al: Fatal hepatitis B virus reactivation in a chronic myeloid leukemia patient during imatinib mesylate treatment. Leuk Lymphoma 2006, 47(1):155-157.

54. Tur-Kaspa R, Burk RD, Shaul Y, Shafritz DA: Hepatitis B virus DNA contains a glucocorticoid-responsive element. Proc Natl Acad Sci U S A 1986, 83 (6):1627-1631.

55. Wasley A, Kruszon-Moran D, Kuhnert W, Simard EP, Finelli L, McQuillan G, Bell B: The prevalence of hepatitis B virus infection in the United States in the era of vaccination. J Infect Dis 2010, 202(2):192-201.

56. Lin SY, Chang ET, So SK: Why we should routinely screen Asian American adults for hepatitis B: a cross-sectional study of Asians in California. Hepatology 2007, 46(4):1034-1040.

57. Hu KQ: Hepatitis B virus (HBV) infection in Asian and Pacific Islander Americans (APIAs): how can we do better for this special population? Am J Gastroenterol 2008, 103(7):1824-1833.

58. Khalili M, Guy J, Yu A, Li A, Diamond-Smith N, Stewart S, Chen M Jr, Nguyen T: Hepatitis B and hepatocellular carcinoma screening among Asian Americans: survey of safety net healthcare providers. Dig Dis Sci 2011, 56(5):1516-1523.

59. Lai CJ, Nguyen T, Hwang J, Stewart SL, Kwan A, McPhee SJ: Provider knowledge and practice regarding hepatitis $B$ screening in Chinese-speaking patients. J Cancer Educ 2007, 22(1):37-41.

60. Dickson RC, Everhart JE, Lake JR, Wei Y, Seaberg EC, Wiesner RH, Zetterman RK, Pruett TL, Ishitani MB, Hoofnagle JH: Transmission of hepatitis B by transplantation of livers from donors positive for antibody to hepatitis $B$ core antigen. The National Institute of Diabetes and Digestive and Kidney Diseases Liver Transplantation Database. Gastroenterology 1997, 113(5):1668-1674

61. Evens AM, Jovanovic BD, Su YC, Raisch DW, Ganger D, Belknap SM, Dai MS, Chiu BC, Fintel B, Cheng Y, et al: Rituximab-associated hepatitis B virus
(HBV) reactivation in lymphoproliferative diseases: meta-analysis and examination of FDA safety reports. Ann Oncol 2011, 22(5):1170-1180.

62. Borentain P, Colson P, Coso D, Bories E, Charbonnier A, Stoppa AM, Auran T, Loundou A, Motte A, Ressiot E, et al: Clinical and virological factors associated with hepatitis $B$ virus reactivation in $\mathrm{HBsAg}$-negative and anti-HBC antibodies-positive patients undergoing chemotherapy and/or autologous stem cell transplantation for cancer. J Viral Hepat 2010, 17(11):807-815.

doi:10.1186/1471-2407-13-534

Cite this article as: Hwang et al:: Trends in hepatitis B virus screening at the onset of chemotherapy in a large US cancer center. BMC Cancer 2013 13:534.

\section{Submit your next manuscript to BioMed Central and take full advantage of:}

- Convenient online submission

- Thorough peer review

- No space constraints or color figure charges

- Immediate publication on acceptance

- Inclusion in PubMed, CAS, Scopus and Google Scholar

- Research which is freely available for redistribution 